\title{
The Effect of Giving Reimprinting Intervention in Changes in Cholesterol Levels
}

\author{
Puteri Indah Dwipayanti, Sutomo \\ Department of Nursing, STIKES Dian Husada, Mojokerto, Indonesia \\ Email: puteri.suhandinata@yahoo.co.id
}

How to cite this paper: Dwipayanti, P.I. and Sutomo (2019) The Effect of Giving Reimprinting Intervention in Changes in Cholesterol Levels. Open Journal of Nursing, 9, 911-924.

https://doi.org/10.4236/ojn.2019.98068

Received: April 29, 2019

Accepted: August 26, 2019

Published: August 29, 2019

Copyright $\odot 2019$ by author(s) and Scientific Research Publishing Inc. This work is licensed under the Creative Commons Attribution International License (CC BY 4.0).

http://creativecommons.org/licenses/by/4.0/

\begin{abstract}
Background: Today's lifestyle changes have resulted in changes in the pattern of diseases from infectious diseases to non-communicable diseases. One disease that threatens the community is hypercholesterolemia. Pharmacological therapy was performed often fails due to non-compliance hypercholesterolemia patients. One of the complementary therapies that can be done is by implementing reimprinting. Reimprinting is a development of the SEFT method (Spiritual Emotional Freedom Technique). Reimprinting is the implementation of SEFT therapy independently. Methods: The research design used was quasy experimental with a Randomized Pretest and Posttest Control Group Design. The variables observed in this study were cholesterol levels (total cholesterol, HDL (High Density Lipoprotein), LDL (Low Density Lipoprotein), triglycerides). The group of respondents in this study was divided into 2 groups, namely group 1 (not given an intervention) and group 2 (the group given the reimprinting intervention). To find out the effectiveness of the reimprinting method, a paired-samples $t$ test was used with a significance of 0.05. Result: The results of the study showed that the administration of reimprinting intervention in hypercholesterolemia patients was effective in reducing total cholesterol levels, increasing HDL (High Density Lipoprotein) cholesterol levels and lowering LDL (Low Density Lipoprotein) cholesterol levels. Conclusion: Reimprinting is one type of complementary therapy that can be done as a support for pharmacological therapy given to hypercholesterolemia patients to improve the success of the therapy. To get optimal results, an active role is needed from health personnel to be able to apply reimprinting therapy, obedience of hypercholesterolemia patients to attend each therapy session, active hypercholesterolemia patients should perform therapy independently and obey any advice has been given by health workers to consume drugs routinely and adopt a healthy lifestyle.
\end{abstract}

\section{Keywords}

Reimprinting, Hypercholesterolemic Patients, Cholesterol Levels in Blood 


\section{Introduction}

Advances in technology that change the lifestyle and socio-economic conditions in Indonesia today have resulted in changes in patterns of disease from infectious diseases to non-communicable diseases which include degenerative diseases and human-made diseases which are the main factors in the problem of morbidity and mortality. Non-communicable diseases accounted for 3 million deaths in 2005, of which $60 \%$ of deaths occurred among people under the age of 70. The World Health Organization estimates that, in 2020, non-communicable diseases will cause $73 \%$ of mortality and $60 \%$ of morbidity in the world. The most affected countries are estimated to be developing countries including Indonesia [1]. Non-communicable diseases that are at risk for the community are heart and blood vessel disease. Cardiovascular diseases are the number one cause of death in developed countries. According to the predictions of the World Health Organization in 2020, coronary heart disease and stroke which are currently the main causes of death in developed countries will become the first cause of death in the world. Many factors can be the cause of coronary heart disease, one of which is atherosclerosis. Atherosclerosis causes a buildup of lipids and fibrous tissue in the coronary arteries, thus narrowing the blood vessel lumen. If the lumen narrows, resistance to blood flow will increase [2]. Hypercholesterolemia is a risk factor for atherosclerosis, heart and blood vessel disease. Hypercholesterolemia is a high level of cholesterol in the blood, which can be reduced through diet modification, physical activity, or drugs. An increase in cholesterol that is high enough in a person can be one of the factors that interfere with health and can even endanger health [3]. Lifestyle Changes of people tend to choose fast food that was fast in service has a unique and delicious taste, and has many alternatives menu are becoming one of the factors that cause non-communicable diseases. This type of fast food actually does not have the nutrients needed by the body. The main content it has is high cholesterol [4]. Cholesterol has been known as the main cause of atherosclerosis, which is the process of calcification and hardening of the walls of blood vessels. Especially the coronary arteries become narrow and block the flow of blood in them. This situation will increase the risk of coronary heart disease. At productive age, coronary heart disease has become a serious health problem in Indonesia. From the results of the 1992 National Household Health survey, cardiovascular disease was the number one cause of death for people over 40 years of age [5].

Hypercholesterolemia occurs due to disorders of fat metabolism which can cause an increase in blood fat levels caused by deficiency of lipoprotein, lipase, LDL (Low Density Lipoprotein) receptor deficiency or can be caused by genetic abnormalities that produce a dramatic increase in liver cholesterol production or a decrease in the liver's ability to cleanse cholesterol from the blood [6]. The prevalence of hypercholesterolemia in the 25 - 34 year age group is $9.3 \%$ and increases according to the age increase of up to $15.5 \%$ in the 55 - 64 year age group [7]. Cholesterolemia or can be called hypercholesterolemia is the main lipid 
fraction which is characterized by increased levels of total cholesterol, LDL cholesterol (Low Density Lipoprotein) and triglycerides and decreased levels of HDL cholesterol (High Density Lipoprotein). Whereas, hyperglycemia is an increase in glucose levels in the blood plasma due to lack of the hormone insulin or body may have enough insulin, but it is not as effective as it should be. The impact of high levels of cholesterol and glucose causes the need for a way to reduce it by treatment [8].

Hypercholesterolemia is closely related to cholesterol levels in the blood. Classification of hypercholesterolemia, namely, mild hypercholesterolemia is characterized by LDL value $140-159 \mathrm{mg} / \mathrm{dL}$, moderate hypercholesterolemia if LDL levels $160-189 \mathrm{mg} / \mathrm{dL}$ and severe hypercholesterolemia LDL levels $>190 \mathrm{mg} / \mathrm{dL}$. LDL cholesterol is the most atherogenic type of cholesterol so it is also called bad cholesterol. LDL cholesterol carries the most cholesterol in the blood. High levels of LDL cholesterol can cause deposition of cholesterol in the arteries. LDL cholesterol is a major risk factor for coronary heart disease as well as the main target in treatment. The prevalence of coronary heart disease in Indonesia is 83,447 thousand and $45 \%$ of deaths from coronary heart disease [9].

Currently, as a treatment for reducing cholesterol levels, synthetic drugs are used, one of which is cholestiramine which can increase HDL cholesterol levels, by binding to bile acids in the small intestine and preventing reabsorption. Most synthetic drugs have side effects [10]. To reduce the risk of side effects that can be experienced by hypercholesterolemic patients, a non-pharmacological method has been developed, namely a low cholesterol diet. A low cholesterol diet is one of the right ways to reduce LDL cholesterol. Dietary modifications that can be done to reduce cholesterol levels include eating low-fat foods, increasing intake of vegetables and fruits that are rich in fiber, and antioxidants. But in practice, low cholesterol diets often fail. This is because patients with hypercholesterolemia tend not to adhere to a low cholesterol diet recommended by health workers. This will indirectly have an impact on the results of the therapy given. Health workers in the matter are nurses, are required to be able to provide a more practical solution that can increase the success of the therapy given. Nurses as nursing care providers are expected to be able to provide nursing care independently in a non-pharmacological context. The nonpharmacological approach is a mandatory intervention that must be carried out on each pharmacological therapy. Included in non-pharmacological treatment is to provide complementary therapy to patients [11].

One of the complementary therapies that can be done is by implementing reimprinting. Reimprinting is a development of the SEFT method (Spiritual Emotional Freedom Technique). SEFT (Spiritual Emotional Freedom Technique) is a revolutionary and spectacular scientific technique because it is known to be very easy and fast to be able to feel the results that can be used to overcome various physical problems, overcome various emotional problems, overcome various problems of family and children and improve achievement. SEFT (Spi- 
ritual Emotional Freedom Technique) consists of 3 stages, namely: The Set-Up, the Tune-in and the Tapping [12]. Reimprinting is an independent implementation of SEFT (Spiritual Emotional Freedom Technique) therapy. In the practice of re-printing a hypercholesterolemic sufferer, you must first understand the SUDS (Subjective Unit of Distress Scale). After understanding the SUDS (Subjective Unit of Distress Scale), then hypercholesterolemic sufferers must understand Psychological Reversal. By understanding SUDS and Psychological Reversal, hypercholesterolemic sufferers will be able to increase their self-limiting, which in the end will be able to apply reimprinting techniques to overcome the health problems experienced.

\section{Methods}

The research design used was quasy experimental with a randomized pretest and posttest control group design for 3 months. The variables observed in this study were cholesterol levels (total cholesterol, HDL cholesterol, LDL cholesterol). The sample in this study was determined using criteria 1) hypercholesterolemic patients, 2) did not experience infectious diseases, 3) able to communicate well, 4) willing to participate in research activities. The respondent group in this study was divided into 2 groups randomly, namely group 1 (not given intervention) and group 2 (given reimprinting intervention). The data collection instrument used is the observation sheet. Cholesterol levels (total cholesterol, HDL cholesterol, LDL cholesterol) from each respondent were collected from respondents as the initial data (pre-test). Furthermore for group 2 (the group given the reimprinting intervention) was given intervention for a period of 3 months. SEFT therapy (Spiritual Emotional Freedom Technique) is carried out every 2 times in 1 week. During the activity, each respondent continued to consume simvastatin and kolestiramin according to advice from health workers. After 3 months from the initial data collection (pre-test), the cholesterol (total cholesterol, HDL cholesterol, LDL cholesterol) from each respondent was collected and used as the final data (post-test). To determine the effect of the reimprinting technique on changes in cholesterol levels (total cholesterol, LDL cholesterol, HDL cholesterol) a paired sample T-test was performed with a significance value of $\alpha=0.05$. If the significance value obtained is $<\alpha=0.05$, it can be concluded that the administration of reimprinting intervention has an influence on changes in cholesterol levels (total cholesterol, LDL cholesterol, HDL cholesterol) of hypercholesterolemic patients.

\section{Ethical Clearance}

This study was approved by local ethics commission is derived from institution STIKES Dian Husada Mojokerto (014/KEDH/IV/2018). Written official permissions were gained from informed consent was obtained from each participant. The patient was informed of the aim of the study and was assured that they had the right to refuse to participate or to leave the study whenever they wished. 


\section{Results}

1) Demographic data

From the results of the study, most of the respondents were male as many as 40 respondents (62.5\%), more than half of the respondents were elderly as many as 35 respondents (54.7\%), most of the respondents were still actively working as many as 51 respondents (79.7\%), some the number of respondents experienced overweight as many as 41 respondents (64.1\%), the majority of respondents had a history of diabetes mellitus as many as 37 respondents (57.8\%), most respondents had diabetes mellitus type 2 as many as 43 respondents (67.2\%) and most respondents experienced hypertension stage 1 as many as 38 respondents (59.4\%) (see Table 1).

2) Effectiveness of reimprinting on changes in cholesterol levels in the body (total cholesterol)

From the results of the study in group 1 (no intervention) it was found that the average total cholesterol level in the initial data collection (pre-test) was 231.3125 with a standard deviation of 13.59421. After 3 months of initial data

Table 1. Demographic data of research respondents.

\begin{tabular}{|c|c|c|c|c|c|}
\hline \multirow[t]{2}{*}{ No } & \multirow[t]{2}{*}{ Demographic data } & \multicolumn{2}{|c|}{$\begin{array}{l}\text { Group } 1 \\
\text { (not given intervention) }\end{array}$} & \multicolumn{2}{|c|}{$\begin{array}{l}\text { group } 2 \\
\text { (given intervention) }\end{array}$} \\
\hline & & Frequency & Percentage & Frequency & Percentage \\
\hline \multirow{4}{*}{1} & Gender & & & & \\
\hline & - Man & 20 & 62.5 & 20 & 62.5 \\
\hline & - Women & 12 & 37.5 & 12 & 37.5 \\
\hline & Age of respondents & & & & \\
\hline \multirow[t]{3}{*}{2} & - Productive age & 14 & 45.2 & 15 & 45.5 \\
\hline & - Elderly & 17 & 54.8 & 18 & 54.5 \\
\hline & Work activities & & & & \\
\hline \multirow[t]{3}{*}{3} & - Work active & 25 & 80.6 & 26 & 78.8 \\
\hline & - Does not work active & 6 & 19.4 & 7 & 21.2 \\
\hline & The incidence of obesity & & & & \\
\hline \multirow{4}{*}{4} & - Normal & 9 & 29.0 & 10 & 30.3 \\
\hline & - Overweight & 20 & 64.5 & 21 & 63.6 \\
\hline & - Obesity & 2 & 6.5 & 2 & 6.1 \\
\hline & History of diabetes mellitus & & & & \\
\hline \multirow{4}{*}{5} & - No history of diabetes mellitus & 13 & 41.9 & 14 & 42.4 \\
\hline & - There is a history of diabetes & & & & \\
\hline & mellitus & 18 & 58.1 & 19 & 57.6 \\
\hline & The incidence of diabetes mellitus & & & & \\
\hline \multirow[t]{4}{*}{6} & - No incidence of diabetes mellitus & 10 & 32.3 & 11 & 33.3 \\
\hline & - Diabetes mellitus type 2 & 21 & 67.7 & 22 & 66.7 \\
\hline & The incidence of hypertension & & & & \\
\hline & - No incidence of hypertension & 2 & 6.9 & 2 & 5.7 \\
\hline \multirow[t]{3}{*}{7} & - Prehypertension & 8 & 27.6 & 9 & 25.7 \\
\hline & - Hypertension stage 1 & 17 & 58.6 & 21 & 60.0 \\
\hline & - Hypertension stage 2 & 2 & 6.9 & 3 & 8.6 \\
\hline
\end{tabular}


collection (pre-test), cholesterol levels (total cholesterol) were re-measured. From the results of the measurement of the final data (post-test) it was found that the average total cholesterol level of the respondents was 230.6250 with a standard deviation of 13.34831. From the results of paired samples t-test, the mean change in total cholesterol level was 0.68750 with a significance value of 0.300 so it can be concluded that for a period of 3 months there was no significant change in cholesterol levels in the study respondents in group 1 (no given intervention). From the results of the research in group 2 (given a reimprinting intervention) it was found that the average total cholesterol level in the respondents before being given a reimprinting intervention was 226.1562 with a standard deviation of 15.57937. After being given a reimprinting intervention for a period of 3 months the average total cholesterol level in the respondents was 224.6875 with a standard deviation of 16.33804 . From the results of paired samples t-test, the mean change in total cholesterol level was 1.46875 with a significance value of 0.025 so that it can be concluded that the administration of reimprinting interventions was effective in reducing total cholesterol levels in the body (see Table 2).

3) Effectiveness of reimprinting on changes in cholesterol levels in the body (HDL/High Density Lipoprotein)

From the results of the study in group 1 (not given an intervention), the mean cholesterol level (HDL/High Density Lipoprotein) in the initial data collection (pre-test) was 51.0625 with a standard deviation of 2.71124. After 3 months of initial data collection (pre-test), cholesterol levels (HDL/High Density Lipoprotein) were re-measured. From the results of the measurement of the final data (post-test) it was found that the average cholesterol level (HDL/High Density Lipoprotein) in the respondents was 50.6875 with a standard deviation of 2.76426. From the results of paired samples t-test, it was found that the average change in cholesterol levels (HDL/High Density Lipoprotein) was 0.37500 with a significance value of 0.097 so that it could be concluded that for 3 months there was no change in cholesterol levels (HDL/High Density Lipoprotein) means for research respondents in group 1 (no intervention). From the results of the research in group 2 (given a reimprinting intervention) it was found that the average cholesterol level (HDL/High Density Lipoprotein) in respondents before being given a reimprinting intervention was 50.1562 with a standard deviation of 5.09338. After being given a reimprinting intervention for a period of 3 months, the mean cholesterol level (HDL/High Density Lipoprotein) in the respondents was 50.7812 with a standard deviation of 5.58647. From the results of paired samples t-test, the mean changes in cholesterol levels (HDL/High Density Lipoprotein) amounted to 0.62500 with a significance value of 0.019 so it can be concluded that reimprinting intervention was proven to be effective for increasing cholesterol (HDL/High Density Lipoprotein) in the body (see Table 3).

4) Effectiveness of reimprinting on changes in cholesterol levels in the body (LDL/Low Density Lipoprotein) 
Table 2. Result of data analysis (paired t test) effectiveness of reimprinting on changes in cholesterol levels in the body (total cholesterol).

\begin{tabular}{ccc}
\hline & $\begin{array}{c}\text { Group 1 } \\
\text { (not given intervention) }\end{array}$ & $\begin{array}{c}\text { Group 2 } \\
\text { (given reimprinting intervention) }\end{array}$ \\
\hline Mean & 0.68750 & 1.46875 \\
Std Deviation & 3.69339 & 3.53767 \\
$\mathrm{t}$ & 1.053 & 2.349 \\
$\mathrm{df}$ & 31 & 31 \\
Sig (2-tailed) & 0.300 & 0.025 \\
\hline
\end{tabular}

Table 3. Result of data analysis (paired t test) effectiveness of reimprinting on changes in cholesterol levels in the body (HDL/High Density Lipoprotein).

\begin{tabular}{ccc}
\hline LDL Cholesterol & $\begin{array}{c}\text { Group 1 } \\
\text { (not given intervention) }\end{array}$ & $\begin{array}{c}\text { Group 2 } \\
\text { (given reimprinting intervention) }\end{array}$ \\
\hline Mean & 0.37500 & -0.62500 \\
Std Deviation & 1.23784 & 1.43122 \\
$\mathrm{t}$ & 1.714 & 1.470 \\
$\mathrm{df}$ & 31 & 31 \\
Sig (2-tailed) & 0.097 & 0.019 \\
\hline
\end{tabular}

From the results of the study in group 1 (not given an intervention), the mean cholesterol level (LDL/Low Density Lipoprotein) in the initial data collection (pre-test) was 15.1250 with a standard deviation of 9.69785. After 3 months of initial data collection (pre-test), cholesterol levels (LDL/Low Density Lipoprotein) were measured again. From the results of the measurement of the final data (post-test) it was found that the average cholesterol level (LDL/Low Density Lipoprotein) in the respondents was 151.5000 with a standard deviation of 9.21779. From the results of paired samples t-test, the mean change in total cholesterol levels was 0.62500 with a significance value of 0.072 so that it could be concluded that for 3 months there was no significant change in cholesterol levels (LDL/Low Density Lipoprotein) in the study respondents in the group 1 (no intervention is given). From the results of the study in group 2 (given a reimprinting intervention) it was found that the average cholesterol level (LDL/Low Density Lipoprotein) in respondents before being given a reimprinting intervention was 149.9375 with a standard deviation of 9.77138. After being given a reimprinting intervention for a period of 3 months, it was found that the average cholesterol level (LDL/Low Density Lipoprotein) in the respondents was 149.2188 with a standard deviation of 9.75419. From the results of paired samples t-test, it was found that the average change in cholesterol level (LDL/Low Density Lipoprotein) was 0.71875 with a significance value of 0.036 so that it can be concluded that reimprinting intervention was effective in reducing cholesterol (LDL/Low Density Lipoprotein) in the body (see Table 4). 
Table 4. Result of data analysis (paired t test) effectiveness of reimprinting on changes in cholesterol levels in the body (LDL/Low Density Lipoprotein).

\begin{tabular}{ccc}
\hline & $\begin{array}{c}\text { Group 1 } \\
\text { (not given intervention) }\end{array}$ & $\begin{array}{c}\text { Group 2 } \\
\text { (given reimprinting intervention) }\end{array}$ \\
\hline Mean & 0.62500 & 0.71875 \\
Std Deviation & 1.89652 & 1.85323 \\
$\mathrm{t}$ & 1.864 & 2.194 \\
$\mathrm{df}$ & 31 & 31 \\
Sig (2-tailed) & 0.072 & 0.036 \\
\hline
\end{tabular}

\section{Discussion}

The research variables measured in this study were blood cholesterol levels in the body consisting of total cholesterol, HDL (High Density Lipoprotein), and LDL (Low Density Lipoprotein).

The results showed that the administration of reimprinting interventions over a period of 3 months in hypercholesterolemic patients proved effective for reducing cholesterol (total cholesterol) with an average change in cholesterol (total cholesterol) level of 1.46875 and sig. (2-tailed) 0.025 . The results showed that the administration of reimprinting interventions over a period of 3 months in hypercholesterolemic patients was proven effective for increasing cholesterol levels (HDL/High Density Lipoprotein) with an average change in cholesterol levels (HDL/High Density Lipoprotein) of 0.62500 and sig values. (2-tailed) 0.019. The results showed that the administration of reimprinting interventions over a period of 3 months in hypercholesterolemic patients was proven effective for reducing cholesterol levels (LDL/Low Density Lipoprotein) with an average change in cholesterol levels (LDL/Low Density Lipoprotein) of 0.71875 and $\operatorname{sig}(2$-tailed) 0.036 .

Hypercholesterolemia occurs due to disorders of fat metabolism which can cause an increase in blood fat levels caused by deficiencies of lipoprotein, lipase, deficiency of LDL cholesterol (Low Density Lipoprotein) receptors or can be caused by genetic abnormalities that produce a dramatic increase in liver cholesterol production or a decrease in the liver's ability to cleanse cholesterol from the blood. The prevalence of hypercholesterolemia in the 25 - 34 year age group is $9.3 \%$ and increases according to the age increase of up to $15.5 \%$ in the $55-64$ year age group. Cholesterolemia or can be called hypercholesterolemia is the main lipid fraction which is characterized by increased levels of total cholesterol, LDL cholesterol (Low Density Lipoprotein) and triglycerides and decreased levels of HDL cholesterol (High Density Lipoprotein). Whereas, hyperglycemia is an increase in glucose levels in the blood plasma due to lack of the hormone insulin or body may have enough insulin, but it is not as effective as it should be [13].

Currently, as a treatment for reducing cholesterol levels, synthetic drugs are used, one of which is cholestiramine which can increase HDL cholesterol levels, 
by binding to bile acids in the small intestine and preventing reabsorption. Most synthetic drugs have side effects. Besides cholestiramine, sismvastatin and gemfibrozil are also given to hypercholesterolemic patients. To reduce the risk of side effects that can be experienced by patients with hypercholesterolemia a nonpharmacological method/complementary therapy has been developed, namely a low cholesterol diet. A low cholesterol diet is one of the right ways to reduce LDL cholesterol. Dietary modifications that can be done to reduce cholesterol levels include eating low-fat foods, increasing intake of vegetables and fruits that are rich in fiber, and antioxidants. But in practice, low cholesterol diets often fail. This is because hypercholesterolemic sufferers tend not to adhere to a low cholesterol diet recommended by health workers. This will indirectly have an impact on the results of the therapy given. In addition to diet therapy, failure to reduce cholesterol levels in patients with hypercholesterolemia is also caused due to patient disobedience in taking drugs that have been prescribed by health workers. Forgetting when taking drugs, being lazy and bored to take drugs is a classic reason that is often raised by hypercholesterolemic sufferers. In addition, the low role of the family to always remind them to routinely consume drugs and low support from family members makes treatment therapy carried out often fail. Health workers in the matter are nurses, are required to be able to provide a more practical solution that can increase the success of the therapy given. Nurses as nursing care providers are expected to be able to provide nursing care independently in a non-pharmacological context. The nonpharmacological approach is a mandatory intervention that must be carried out on each pharmacological therapy. Included in non-pharmacological treatment is to provide complementary therapy to patients [14].

One of the new methods developed to improve the success of pharmacological therapy carried out in patients with hypercholesterolemia is to use the technique of printing. Reimprintring is a technique developed to recondition the imprint that exists in humans. Imprint or more commonly referred to as imprinting/imprinting/imprinting is a memory captured by all human senses which are then stored in the human brain. An imprint is an important event or experience in the past that shapes beliefs or parts of belief. According to Joe Vitale [15], human life is indirectly influenced by programs obtained at the age of the first 6 years of human life. Konrad Lorenz [15] believes that imprints are formed neurologically in certain critical periods and once that critical period is exceeded, anything that has been imprinted becomes permanent and cannot change again. Imprint can be a positive event that forms a useful belief (empowering belief), but it can also become traumatic event can lead to limiting belief of people.

Reimprinting is a development of the SEFT method (Spiritual Emotional Freedom Technique). SEFT is a revolutionary and spectacular scientific technique because it is known to be very easy and fast to be able to feel the results ( 5 to 25 minutes) that can be used to overcome various physical problems, overcome various emotional problems, overcome various problems of family and children and improve achievement. SEFT consists of 3 stages, namely: The 
Set-Up, The Tune-in and The Tapping [12]. Reimprinting is the implementation of SEFT therapy independently. In the practice of re-printing a hypercholesterolemic sufferer, you must first understand the SUDS (Subjective Unit Of Distress Scale). After understanding about SUDS, then we must understand about Psychological Reversal. By understanding SUDS and Psychological Reversal, hypercholesterolemic sufferers will be able to increase their self-limiting, which in the end will be able to apply reimprinting techniques to overcome the health problems experienced.

SUDS (Subjective Unit of Distress Scale) is a measuring tool that can be used to measure the extent of anxiety or fear experienced by someone. Hypercholesterolemic sufferers can begin to measure the level of anxiety and fear they experience due to hypercholesterolemia that is experienced. Measurements can be done independently or together with family members/health workers. By knowing the level of anxiety experienced, the hypercholesterolemia sufferers will gain self-confidence (self-confidence). Self-confidence to be able to analyze the conditions of anxiety and fear that is experienced due to sickness will bring enthusiasm in someone to try to recover or be free from the disease they experience. The next step is to do psychological reversal in hypercholesterolemic patients. Anxious conditions experienced by a hypercholesterolemic sufferer can make a self-concept become negative. Concrete forms that are evidence of psychological reversal possessed by hypercholesterolemic patients are reluctant to consume drugs prescribed by health workers, are lazy to take medication, are bored to take drugs regularly and are not doing low cholesterol diet therapy recommended by health personnel. By understanding these 2 things, a hypercholesterolemic sufferer will be able to increase the self-limiting they have.

Reimprinting is basically not a therapy done to cure a disease. Reimprinting is a technique that can be implemented as a complementary therapy in hypercholesterolemic patients. This technique teaches patients with hypercholesterolemia to be able to do healing on themselves. The reimprinting technique has a principle similar to acupuncture. Reimprinting views that if the body's energy flow is disturbed because it is triggered by past memories or trauma stored in the subconscious, then a person's emotions will become chaotic. Starting from the light, like feeling lazy, not motivated to do something, to the heavy, such as depression, phobia, excessive anxiety and prolonged emotional stress. Actually, all of these causes are simple, namely the disruption of the body's energy system. Because of that the solution is also simple, neutralizing the energy disturbance with reimprinting. Energy flow that is clogged at several key points of the body must be freed, until it flows again smoothly. The way to free it is by tapping lightly using two fingertips (tapping) in certain body parts. The following is a description of how to do SEFT to free up the flow of energy in the body, which will free emotion from various negative conditions. The 3 stages in re-printing include the set-up, the tune-in and tapping.

The first stage is the Set-Up. At this stage, hypercholesterolemic sufferers must overcome the negative perceptions they have. This aims to ensure that the 
body's energy flow is directed appropriately. This step is done to neutralize "Psychological Reversal" or "Psychological Resistance" (usually in the form of spontaneous negative thoughts or negative unconscious beliefs). Examples of this psychological reversal include: I could not be as healthy as when I was young again, I could not recover from hypercholesterolemia, I was angry with myself for having hypercholesterolemia, I gave up on my current health condition. The Set-Up actually consists of 2 activities, namely to say The Set-Up Word with great enthusiasm, sincerity and surrender 3 times. In religious language, The Set-Up Words is a prayer of submission to God, that whatever problems and pain are experienced at this time, we sincerely accept and we give up healing to God. The Set-Up must be spoken with feeling to neutralize Psychological Reversal (negative beliefs and thoughts). Second, while feeling The Set-Up Word with feeling, the hypercholesterolemic sufferer presses the chest, precisely in the "evening spot" (pain point, located around the upper chest which if pressed feels a bit painful), or tapping with two fingertips in the section "Karate chop". Examples of set-up sentences for physical problems: "Oh my God, even though my head is often dizzy from hypercholesterolemia, I sincerely accept this dizziness, God, I leave all this to you". Example of a set-up sentence for an emotional problem: "Oh my God, even though I am anxious about this disease, I sincerely accept my anxiety, I surrender to You the peace of my heart".

The next stage is The Tune-In. For physical problems, doing a Tune-in by feeling the pain that is experienced, then directing the mind to the place of pain, coupled with the heart and mouth say: "Oh God, I am sincere, I surrender" or "Oh God I sincerely accept my pain, I surrender to You my healing”. For emotional problems, Tune-in is done by thinking of certain specific things or events that can generate negative emotions that we want to eliminate. When there is a negative reaction (anger, sadness, fear, etc.), our heart and mouth say, "My God, I am sincere, I surrender". Along with this Tune-in, we take the third step, tapping. In this process (Tune-in which is accompanied by tapping), we neutralize negative emotions or physical pain.

The last step is the tapping which is the core of the reimprinting technique intervention. Tapping is tapping lightly with two fingertips at certain points on the body while continuing to Tune-in. these points are key points of "The Major Energy Meridians", which if we tap several times will have an impact on neutralizing emotional disturbances or the pain we feel. Tapping causes the body's energy flow to run normally and balance again. The points that will be given light beats/tapping are in the head, chest area and hands. At the head of these points consist of a CR (Crown) point, namely the point at the top of the head (crown); EB point (Eye Brow) is the starting point of the eyebrow, near the base of the nose; the point of SE (Side of the Eye) is the point above the tip of the outer eye bone; UE point (Under the Eye) which is the point right in the lower bone of the eyelid; UN point (Under the Nose) is the point that is located just below the nose and point $\mathrm{Ch}$ (Chin), which is the point between the chin and the 
lower lip [12].

At the chest, the tapping points consist of a $\mathrm{CB}$ point (Colar Bone), which is the point at the end where the breast bone and first rib meet; UA point (Under the Arm) that is the point under the armpit parallel to the nipple (male) or right at the bottom of the bra strap (female) and BN point (Below Nipple) which is the point that is $2.5 \mathrm{~cm}$ below the nipple (male) or on the border between the breastbone and the lower part of the breast [12]. In the hand there are 9 tapping points which consist of IH point (Inside of Hand) which is the point that is located on the inside of the hand that borders on the palm; OH point (Outside of Hand) which is the point on the outside of the hand bordering the palm; Th point (Thumb) is the point that is located on the thumb on the outer side of the bottom of the nail; IF point (Finger Index) is the point on the index finger on the outside of the lower part of the nail (on the part facing the thumb); the point MF (Middle Finger) is the point that is located on the middle finger on the outside side of the bottom of the nail (on the part facing the thumb); RF point (Finger Ring) is the point that is located on the ring finger on the outer side of the bottom of the nail (in the part facing the thumb); point BF (Baby Finger) is the point that is located on the little finger on the outside side of the bottom of the nail (in the part facing the thumb); the point of KC (Karate Chop) is the point that is located next to the palm, the part used to break the beam in karate sports and the GS point (Gamut Spot) which is the point between the extension of the ring finger and the bone of the little finger. Especially for Gamut Spot, while tapping these points, we do the 9 Gamut Procedure. These are 9 movements to stimulate the brain. Each movement is intended to stimulate certain parts of the brain. The nine movements are carried out while tapping on one of the body's energy points called "Gamut Spot". The nine movements are to close the eyes, open the eyes, move the eyes firmly to the lower right, the eyes are moved strongly to the lower left, rotate the eyeball clockwise, rotate the eyeball counterclockwise, mutter rhythmically for 3 seconds, count 1, 2, 3, 4, 5 then ended with another mutter for 3 seconds. The 9 Gamut Procedure in contemporary psychotherapy techniques is called the EMDR (Eye Movement Desensitization Repatterning) technique. After completing the 9 Gamut Procedure, the final step is to repeat tapping from the first point to the 17th (ending in karate chop). And it ends with taking a deep breath and exhaling it while giving thanks to God.

Reimprinting is one of the complementary therapies that can be done by health workers to hypercholesterolemic patients. To be able to carry out re-printing, a health worker must attend a seminar and training activity related to printing. This is so that health workers understand correctly about reimprinting techniques so that health workers can implement reimprinting to patients who are handled and can teach hypercholesterolemic sufferers how to do their own reimprinting. To get optimal results, hypercholesterolemic sufferers must routinely reimprinting themselves. 1 - 2 times re-printing in 1 day, will have a positive impact on the health conditions of hypercholesterolemic patients. 
Reimprinting will not be able to cure the disease or reduce cholesterol levels of hypercholesterolemic patients, but printing can stimulate the brain to create positive things about the health conditions of hypercholesterolemic patients. Reimprinting helps hypercholesterolemic sufferers to build positive perceptions and beliefs related to the health conditions of hypercholesterolemic patients. With this, hypercholesterolemic patients will be motivated to take drugs prescribed by health professionals and begin to adhere to therapy on a low cholesterol diet.

\section{Conslusion}

The results of the study showed that the administration of reimprinting intervention in hypercholesterolemic patients was effective in reducing total cholesterol levels, increasing HDL cholesterol levels and lowering LDL cholesterol levels. Reimprinting is one type of complementary therapy that can be done as a support for pharmacological therapy hypercholesterolemia patients to improve the therapy successfully. To get optimal results, an active role is needed from health personnel to be able to apply reimprinting therapy, obedience of hypercholesterolemia patients to attend each therapy session, active hypercholesterolemia patients should perform therapy independently and obey any advice has been given by health workers to consume drugs routinely and adopt a healthy lifestyle.

\section{Conflicts of Interest}

The authors declare no conflicts of interest regarding the publication of this paper.

\section{References}

[1] Muthiin, M.A., Fitriani, I.D., Auliya, I. and Sutomo, M. (2017) Effectiveness of Giving SEFT Therapy (Spiritual Emotional Freedom Technique) against Cholesterol Levels in Blood in Patients with Cholesterol. Journal of Nursing and Midwifery, 8.

[2] Lintong, P. (2009) The Development of the Concept of the Pathogenesis of Atherosclerosis. Journal of Biomedicine, 1.

[3] Assagaf, K.K. (2015) Effectiveness Test of Ethanol Extract of Tamarind Leaves (Tamarindus indica Linn.) against the Decrease of Blood Cholesterol Levels in Male White Rat Galur Wistar (Rattus norvegicus). Pharmacon, 4.

[4] Oktaviani, W.D. (2012) Relationship between Fast Food Consumption Habits, Physical Activity, Consumption Patterns, Characteristics of Adolescents and Parents with Body Mass Index (BMI) (Case Study on Students of Semarang 9 High School in 2012). Public Health Journal of Diponegoro University, 1.

[5] Nurhidayat, S. (2014) Risk Factors for Cardiovascular Disease in Adolescents in Ponorogo. World Journal of Nursing, 2, 40-47.

[6] Yani, M. (2015) Cholesterol Level Control in Hypercholesterolemia. Journal of Achievement Sports, 11.

[7] Apriyanto, D.R. and Frisqila, C. (2016) Comparison of the Effectiveness of Red Dragon Fruit Extract and Fermentation on Decreasing Low Density Lipoprotein 
(LDL) Cholesterol Levels in White Mice Made by Hypercholesterolemia. Tunas Medika Journal of Medicine \& Health, 3.

[8] Asvita, S.M. and Berawi, K.N. (2017) Effectiveness of Dutch Eggplant Extract to Reduce Blood Glucose and LDL Cholesterol Levels in Obese Patients. Medical Journal of Lampung University, 5, 102-106.

[9] Yuliani, F., Oenzil, F. and Iryani, D. (2014) Relationship between Various Risk Factors for the Incidence of Coronary Heart Disease in Patients with Type 2 Diabetes Mellitus. Andalas Health Journal, 3.

[10] Putri Dwiyanti, S.H. (2014) Test the Effectiveness of Aloe Vera Extracts on Various Doses in Increasing Cholesterol Levels in Hypercholesterolemic White Mice.

[11] Widyatuti, W. (2008) Complementary Therapy in Nursing. Indonesian Nursing Journal, 12, 53-57. https://doi.org/10.7454/jki.v12i1.200

[12] Zainuddin, A.F. (2009) Spiritual Emotional Freedom Technique. Afzan Publishing, Jakarta.

[13] Bantas, K., Agustina, F.M.T. and Zakiyah, D. (2012) Risk of Hypercholesterolemia in Workers in Industrial Estates. Public Health: National Public Health Journal, 6, 219-224. https://doi.org/10.21109/kesmas.v6i5.87

[14] Anggraini, Y.D. (2015) The Effect of Leaflet Use as a Health Education Media towards Compliance of Therapy and Decreasing Cholesterol Levels of Hypercolesterolemia Patients in Tegalrejo Yogyakarta Puskesmas. Doctoral Dissertation, Faculty of Medical and Health Science, Muhammadiyah Yogyakarta University, Bantul.

[15] Rofacky, H.F. and Aini, F. (2015) Effect of Spiritual Emotional Freedom Technique (SEFT) on Blood Pressure in Hypertensive Patients. Sudirman Nursing Journal, 10, 41-52. 